\title{
Saving the Lost Generation of Syria
}

\author{
Kanawati Y* \\ Peachtree Family Psychiatry Clinic, Director, USA \\ *Corresponding author: Yassar Kanawati, MD, Peachtree Family Psychiatry Clinic, \\ Director, Atlanta, GA, USA, Tel: 770-380-0635; E-mail: yassar.kanawati@att.net
}

\section{News}

Volume 1 Issue 1

Received Date: November 04, 2017

Published Date: November 29, 2017

DOI: $10.23880 / \mathrm{mhrij}-16000111$

\section{Abstract}

The war in Syria has reached intolerable levels of human suffering and despair. Hundreds of thousands of Syrians have been killed, hundreds of thousands have been trapped in besieged areas, and tens of thousands have been tortured. Children living through wars and conflict suffer many consequences including post-traumatic stress symptoms, psychosomatic symptoms, depression, anxiety, disturbed play, and behavioral, emotional, and sleep problems, suicide risk, substance use and physical health risks. This paper sheds some light on the best practices for trauma recovery, including Psychological treatments to Syrian refugees carriedon by SAMS (Syrian American Medical Society).

Keywords: Childhood; Trauma; Family; Safety

\section{Introduction}

The war in Syria has reached intolerable levels of human suffering and despair. Hundreds of thousands of Syrians have been killed, and hundreds of thousands have been trapped in besieged areas. UNICEF estimates that some 8.4 million Syrian children, more than $80 \%$ of the Syrian child population, have now been affected by the conflict in Syria [1].

"In Syria, violence has become common place, reaching homes, schools, hospitals, clinics, parks, playgrounds and places of worship. Nearly 7 million children living in poverty, making their childhood one of loss and deprivation [2]. Peter Salma, UNICEF regional director of Middle East. The numbers of wounded survivors, many with amputations, severe burns, or paralysis, cannot yet be assessed; and at least 13 million Syrians have been forcefully displaced within Syria and into its neighboring countries. Gross violations of international law, such as chemical attacks on civilians, targeting of health facilities and health personnel, widespread breach of medical neutrality, and blocking access of whole communities to food, water, medicine, and health care, have been used as methods war. The global health community cannot stand by. It is our responsibility to save the lost generation in Syria [1], the survivors of multiple and severe traumas and losses.

Many studies examined the effects of exposure to war, conflict, and terrorism on young children which all revealed a wide array of consequences including posttraumatic stress symptoms, psychosomatic symptoms, depression, anxiety, disturbed play, and behavioral, emotional, and sleep problems, Substance use, suicide risk, and Physical disease risk $[3,4]$. These mental health and Physical risks following exposure to war and conflict are also seen among displaced populations and among refugees. War can have devastating effects because of the effects on parents, survival needs, and harm to fundamental systems that nurture and protect child development. The greatest effects on children occur when parents are killed, harmed, terrified, or unable to function and when the child experiences violent harm to them or loved ones, threats of such violence, or engages in harming others. Children's' responses to the war trauma will vary by the developmental level and personality of the child as well as the situation [5]. 


\section{Mental Health \& Human Resilience International Journal}

Effects vary by the degree of exposure, damage to basic systems for human development, and understanding by the individual child; as well as previous traumatic experiences. Children of all ages will experience anxiety, and in some cases panic, if separated from the people who represent their "secure base" $\sim$ usually parents $[6,7]$. Unfortunately, adults sometimes underestimate the impact of trauma on children and youth. Resilience is facilitated by meeting survival needs and restoring basic protective systems for child development, by safety, quality parenting, daily routines, opportunities to go to school and play, etc.

\section{Best Practices for Trauma Recovery}

Community: Ensure the presence of supportive care givers, with a solid caring and nurturing relationship with the child. (the most important factor contributing to a child's resilience is the child's capacity for expression, attachment, and trust that comes from stable, caring and nurturing relationship with adults) [4]. Children need Safe, Secure, Stable Environments and Communities via (1) Deep understanding of the Local Culture and Practices (Religion, Family structure), (2) Rebuild Social Networks (friends, school, neighbors, play, sport) that promote Support, Healing, Reconstruction, Self-worth, and Trust, (3) Re-establish a Sense of Normalcy, including Daily Routine of Family, Community, and Life (School, meals, Sport), and (4) Education and School: where schooling represent a state of Normalcy, a chance to be with friends, and enjoy their support and encouragement, where they can develop new coping and survival knowledge that builds Child's Personality, talents, Physical and Mental Abilities to their fullest potential.

Family and Individual Therapy: (1) Family Therapy: Parents always must be involved, (2) Cognitive Behavioral Therapy (IT, GT): Relaxation Technique, correcting distorted thinking, Narrative and Storytelling about Trauma, (3) Play/Art Therapy: for young children, and (4) Medication: for Severe Symptoms of Anxiety, PTSD, Depression, Aggression, Anger.

\section{SAMS (Syrian American Medical Society) Psychosocial Services Provided to the Syrian Refugees}

SAMS established four programs to provide treatment and care to the Syrian Communities in Jordan, Lebanon, and inside Syria $[8,9]$. Each program consists of Social
Workers, Psychotherapists and Psychiatrists. Services provided are:

Social Support: To facilitate Resilience, children need to be provided with a Stable environment, and a loving and nurturing community. SAMS outreach workers would make visits to the Syrian Families to: (1) Provide some families with food, especially in the besieged areas to prevent sexual exploitation of the children as price for their food, (2) Assess the family members for PTSD/ Depression, (3) Evaluate the need for any Medical Assistance and referring them to Medical professionals in the community, (4) Assist the children to pursue Education: we rent schools to provide the children with basic Education needs, and (5) Assist with Vocational Training for the Widows. Give a man a fish and you feed him for a day. Teach a man to fish and you feed him for a lifetime. (Chinese Proverb)

Therapy/Treatment: (1) Individual Supportive and Cognitive Behavioral Therapy, (2) Family Therapy (Supportive, Psycho educational): for the parents whose children with symptoms of Depression, PTSD, behavioral troubles, bedwetting, and refusal to go to school, (3) Group Therapy (Cognitive, Behavioral, Supportive): for Mothers and Teenagers survivors of multiple losses and traumas, (4) Play/Art Therapy for young children, and (5) Medications: It is extremely difficult to provide medications to the inside of Syria due to Border's Closure, especially in South Syria, close to Jordan. SAMS members have been trying to provide best treatment practices to the Syrian refugees, in spite our limited budget and resources, we invite everyone in the international community to join us in saving the Lost Generation in Syria.

\section{References}

1. Bhutta ZA, Keenan WJ, Bennett S (2016) Children of war: urgent action is needed to save a generation. The Lancet 388(10051): 1275-1276.

2. Essentials for Childhood Framework.

3. Teen Resilience.

4. Effective Treatments for Youth Trauma.

5. New Study Documents Psychological Horrors of SixYear War on Syrian Children.

6. Syrian Refugee Kids Are Scarred by War. This Organization Gives Them a Place to Be Kids Again. 


\section{Mental Health \& Human Resilience International Journal}

7. Syrians Struggle to Make a New Home in Germany.

8. Jabbour S, Leaning J, Nuwayhid I, Horton R, Das P (2016) The Lancet-American University of Beirut Commission on Syria: a new role for global health in conflict and a call for papers. The Lancet 388(10063): 2967-2968.

9. SAMS - Syrian American Medical Society.

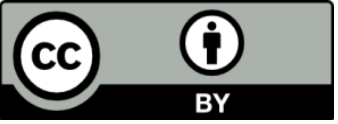

